IJ§ER

ISSN: 2149-5939
International Journal of Social Sciences and Education Research

Online, http://dergipark.gov.tr/ijsser

Volume: 1(1), 2015

\title{
Avrupa Birliği ekonomik entegrasyon sürecinde ortaya çıkan problemle- rin Yunanistan örneği bağlamında değerlendirilmesi
}

\section{European economic integration process problems arising in the context of Greece case evaluation}

\author{
Rıdvan Karacan ${ }^{1} \quad$ Ersin Uğurkan²
}

Received Date: $01 / 01 / 2015$

Accepted Date: 01 / 02 / 2015

\begin{abstract}
$\ddot{O} z$
Ekonomik ve siyasal oluşumların ortak karakteristik yapısında, coğrafi yakınlık, ortak tarih, ortak kültür din ve dil unsurlarını bir arada görmek mümkündür. Bu şekilde birden fazla ülkenin bir araya gelmesiyle oluşan topluluklar kendilerinden olmayan diğer dünya devletlerine veya tek başına mücadele edemedikleri büyük ülkelere karşı ekonomik, siyasi, askeri alanda bir üstünlük sağlamayı amaçlamaktadır. 1951 Yılında Kömür Çelik Topluluğu şeklinde ortaya çıkan, önce ekonomik sonra siyasal birliktelik amaçlanan Avrupa Birliği Yunanistan'da yaşanan ekonomik kriz sonrası ilk kez ciddi bir sorunla karşı karşıya kalmıştır. Kurulduğundan bu yana hem ekonomik hem de siyasal anlamda her şeyin adeta güllük gülistanlık olduğu Avrupa Birliği karşısına çıkan ilk krizde çözüm üretmekte yetersiz kalmıştır. Bu durum ekonomik bütünleşmenin yalnızca para politikasıyla sınırlı kaldığı, gerek maliye politikalarında gerekse siyasi bütünleşme yolunda aynı uyumun sağlanamadığını ortaya koymuştur. Bu bağlamda çalışmada Yunanistan örneğinden yola çıkılarak bu gerçek vurgulanmak istenmiştir.
\end{abstract}

Anahtar sözcükler: Avrupa Birliği, Yunanistan, ekonomik birlik, siyasal birlik

\begin{abstract}
In the common characteristic structure of economic and political formations, it is possible to see geographic proximity, common history, common culture, language and religious elements together. Communities that are formed, in this way, by a combination of more than one country aim to ensure economic, political and military superiority over other countries that do not involve in or over the big countries that they cannot fight alone. European Union Firstly That was emerged as Coal and Steel Community in 1951. EU is integration process. First stage of integration is economic. End of integration process is political unity. But EU has met economic crise of Greece. EU has negotiated with Greece in order to take place economic measures for long time. Finally, Greece has convinced by EU on economic measures. However. EU have debated removing of Greece from Monetary Union. Actually, EU behaved mistakenly about financial policy that attıtude is analyzed. Furthermore We stressed that in the context; EU isn't able to harmony in political integration and financial policy.
\end{abstract}

Keywords: European Union, Greece, economic unity, political unity

\section{Giriş}

İkinci dünya savaşı sonrası dönemin en önemli sanayi hammaddeleri olan kömür ve çeliğin tek elden çıkmasını sağlamak, oluşabilecek uyumsuzlukları engellemek amacıyla Almanya, Fransa, İtalya, Hollanda, Belçika ve Lüksemburg arasında Avrupa Kömür Çelik Topluluğu kurulmuş böylece Avrupa Birliğinin ilk temeli atılmıştır. Daha sonraki süreçte kömür ve çeliğin yanı sıra diğer sektörlerde de ekonomik birliktelik oluşturmak amacıyla 1957 yılında Roma Anlaşması

\footnotetext{
${ }^{1}$ Assist. Prof. Dr., Kocaeli University, KOCAELI/TURKEY, rkaracan@,kocaeli.edu.tr

${ }^{2}$ Lecturer, Kocaeli University, KOCAELİTURKEY, eugur@kocaeli.edu.tr
} 
Karacan, R., Uğurkan, E. (2015). European economic integration process problems arising in the context of Greece case evaluation. International Journal of Social Sciences and Education Research, 1 (1), 230-240.

Avrupa Ekonomik Topluluğu; 1958 yılında Avrupa Atom Enerjisi Topluluğu Kurulmuştur. İlerleyen süreç de bu üç topluluk Avrupa Topluluğu adı altında birleşerek faaliyetlerini sürdürmüştür. $\mathrm{Bu}$ arada çeşitli ülkelerin katılımıyla üye sayısı artarken 1981 yılında Yunanistan birliğe üye olmuştur. 1995 yılında Avrupa Birliği ismini alan topluluk önce parasal ve ekonomik bütünleşme sonrasında siyasal birlikteliği amaçlamıştır.

Lizbon Antlaşması'nın onay sürecinin devam ettiği 2008 yılında, AB ülkelerini etkilemeye başlayan küresel mali kriz, başlangıçta Kıta Avrupası'nı çok fazla etkilemeyecek bir “Anglo-Sakson Kapitalizmi” krizi olarak algılandıysa da, zamanla AB'nin içinde bulunduğu sorunları önemli ölçüde artırdı (Arısan, 2010, s.2). Özellikle birliğe üye Güney Avrupa ülkelerinde krizin etkisiyle yaşanan sorunlar ekonomik entegrasyon sürecini olumsuz yönde etkilemiş başta Yunanistan olmak üzere, Almanya'nın liderliğinde birlik bu ülkelere karşı sıkı kemer sıkma politikası ya da acı reçete olarak adlandırılan ekonomik önlemleri uygulatmıştır. İspanya ve Portekiz gibi ülkeler acı siyasi bedellere karşı, bu önlemlerle toparlanma sürecine girmiştir. Yunanistan özelinde ise, süreç daha farklı seyir izlemiş, Birliğin sıkı ekonomik önlemlerini uygulayan Yunanistan'dan da Yeni Demokrasi Partisi liderliğindeki hükümet son seçimlerde bunun bedelini ağır yenilgi ile ödemiş Birliğin sıkı ekonomik politikalarına karşı söylem geliştiren Çipras liderliğindeki Sryiza seçimleri kazanmış bu süreçten sonra Yunanistan'ın bu önlemlere karşı direnmesi ve fakat bir türlü kriz girdabından kurtulamaması parasal birlikten çıkmak için referanduma gitmesi gibi, gelişmeler Avrupa Birliğinin siyasi birliği hedeflerken ekonomik entegrasyonunu sekteye uğratmıştır. Bu amaçla çalışmada Yunanistan örneğinden yola çıkılarak Avrupa Birliğinin gerek ekonomik gerekse siyasal olgunluğa ulaşamadığı örneklerle gösterilmeye çalışılacaktır.

\section{Ekonomik ve siyasal entegrasyon kavramları ve Avrupa Birliği}

Ekonomik ve siyasal oluşumların ortak karakteristik yapısında, coğrafi yakınlık, ortak tarih, ortak kültür din ve dil unsurlarını bir arada görmek mümkündür. Bu şekilde birden fazla ülkenin bir araya gelmesiyle oluşan topluluklar kendilerinden olmayan diğer dünya devletlerine veya tek başına mücadele edemedikleri büyük ülkelere karşı ekonomik, siyasi, askeri alanda bir üstünlük sağlamayı amaçlamaktadır.

İkinci Dünya Savaşından bu yana çok sayıda ulus devlet bağımsızlığını ilan etmiştir. Bağımsız devletlerin sayısı 1945'teki sayının neredeyse üç misli artmıştır. Bunun yanında bazı ulus devletlerinde bağımsızlık hareketlerinin tam tersi ekonomik siyasal entegrasyon adı altında birleştikleri görülmüştür. Bunun en bariz örneği Avrupa Birliğidir (Brou ve Ruta, 2007,s.1144). Dünyada ekonomik anlamda bütünleşme hareketleri ağırlıklı olarak 1980 ve sonrası ortaya çıkmıştır. Ekonomik anlamda başlayan bütünleşme hareketleri, gelişen teknoloji ve iletişim araçları sayesinde siyasal, sosyal ve kültürel alanlarda kendini göstermiştir (Cornia, 2011,s.1).

Ekonomik entegrasyon ülkeler arasındaki tarifeler, tarife dışı engeller, ortadan kaldırmakta; iş gücünün ve üretimin bir ülkeden bir başka ülkeye rahatça geçebilmesine imkan tanımakta; böylece hem ticaret önündeki bürokrasiye bağlı gecikmeler ortadan kalkmakta hem de ülkelerin refah düzeyi yükselmektedir (Jovanovic, 2005, s.3). Ekonomik bütünleşme sonrası, ülkeler arasında yatırım firsatları artmakta, kaynaklar daha etkin ve verimli kullanılmakta, ticari engeller ve bunlara bağlı maliyetler düşmekte, iç piyasalarda artan rekabet sonrası kalite artmakta fiyatlar düşmekte, teknik bilgi alışverişi kolaylaşmakta, böylece tüketici faydasını maksimize ederken, üretici ölçek ekonomilerinden dolayı daha fazla kar etmektedir (Jovanovic, 2004,s.11). Siyasi bütün- 
Karacan, R., Uğurkan, E. (2015). Avrupa Birliği ekonomik entegrasyon sürecinde ortaya çıkan problemlerin Yunanistan örneği bağlamında değerlendirilmesi. International Journal of Social Sciences and Education Research, 1 (1), 230-240.

leşme ise birkaç ulusal devletin siyasi aktörlerinin beklentileri ve sadakatleri ile siyasal eylemlerinin merkezi bir yönetime devretmeleri şeklinde tanımlanabilir. Böylece önceden var olan ulusal devletler siyasi oluşum sürecinde yeni bir siyasi topluluk haline dönüşmektedir (Hass, 1958,s.16).

Günümüzde ekonomik ve siyasal bütünleşme anlamında yol alan en bariz örnek Avrupa Birliği’dir. 1951 Yılında ekonomik anlamda bütünleşme hamlesiyle başlayan süreç ilerleyen aşamalarda siyasal bütünleşmeye doğru yönelmiştir. Avrupa Birliği beş aşamalı bir bölgesel ekonomik entegrasyon projesidir. Bölgesel ekonomik entegrasyon için; birinci aşamada serbest ticaret politikası, ikinci aşamada gümrük birliği, üçüncü aşamada sermaye ve diğer üretim faktörlerin serbest dolaştığı genel piyasa sürecidir. Dördüncü aşamada para birliği ve beşinci aşama siyasal birliktir (Yaşar, 2015). AB'nin başarıya ulaşması için bu beş aşamanın başarıyla tamamlanması gerekiyor.

Avrupa'nın entegrasyon sürecinde üç dinamik önemli etkendir. Bunlardan ilki genişleme ve derinleşme süreçleri arasındaki etkileşimdir. Diğeri ise Avrupa dışı ve Avrupa içi gelişmeler arasındaki etkileşimdir. Son dinamik ise krizlerin meydana getirdiği etkilerle ilgilidir. Çünkü krizler $\mathrm{AB}$ tarihinin ayrılmaz parçasıdır ve her krizden çıkış, beraberinde yeni kurumlar ya da var olan kurumlarda değişikliği zorunlu hale getirmiştir. Bu dinamikler bu süreçte sancılı da olsa yeni bir entegrasyon aşamasında itici güc olmuştur. Zira Avrupa entegrasyonunun enerjisinde krizler önemli etkendir. Avrupa entegrasyon süreçleri incelendiğinde ortaya çıkan sorunları çözümüne yönelik, çıkar yol aranarak çözüm üretilmiştir. Bu da entegrasyon sürecinin normal şartlarda gerçekleşmediği aksine krizlerden beslendiğini göstermektedir (Özdemir; 2002,s.254).

Avrupa bütünleşmesi, 21. yüzyıla büyük başarılarla ve kapsamlı biçimde dönüşüm geçirerek başlamıştır. İlk olarak, Avrupa Birliği (AB) üyesi 11 ülke, ortak para birimi avroyu kullanmaya başlamıştır. Avronun ortak para birimi olarak kabul edilmesi, ekonomik kazanımların da ötesinde siyasi ve sosyolojik mesajlar içermektedir. Zira avro, federal Avrupa destekçileri tarafından bir egemenlik simgesi olarak, ekonomik kazanımlarının ötesinde ortak bir siyasal yapılanma ve kimlik-inşa unsuru olarak değerlendirilmiştir. Üye ülkeler, Avro bölgesinin inşası ile birlikte para politikası ile ilgili her türlü tasarruf haklarını ulus üstü kurumlara devretmiştir. Bu bağlamda, Avrupa Merkez Bankası (AMB), tüm üyeler adına para politikası konusunda karar verme yetkisini eline almıştır. Para politikasının Avrupa Merkez Bankası'na devredilmesi, ekonomik bütünleşme yolunda Avrupa'yı en üst düzeyde ortaklığa taşıyan bir gelişme olmuştur. Ancak para politikasıyla uyumlu bir yetki transferi maliye politikası alanında sağlanamamış, avro kullanan üye ülkeler başta vergi politikası, iş gücü piyasasının düzenlenmesi ve rekabet politikaları olmak üzere, maliye politikasına ilişkin bir çok alanda ulus-devlet düzeyinde yetkilerini kullanmışlardır (Öniş ve Kutlay, 2012,s.4-7).

\section{Avrupa Birliği ortak para ve maliye politikaları}

Avrupa Birliği üye olabilmek için ekonomik kriterler dâhilinde yerine getirilmesi gereken para ve maliye politikaları vardır. Ekonomik ve Parasal Birliğinin istikrarının devamlılığı için 1993 yılında Maastricht anlaşması yürürlüğe girmiştir. Böylece üye ülkeler arasında para ve maliye politikalarında eşgüdüm hedeflenmiş̧ir. Buna göre;

- Üye ülke borçlarının GSYİH'sına oranı \%60’1 geçmemelidir,

- Bütçe açı̆̆ının GSYİH'sına oranı \%3'ü geçmemelidir (Prammer, 2009,s.125). 
Karacan, R., Uğurkan, E. (2015). European economic integration process problems arising in the context of Greece case evaluation. International Journal of Social Sciences and Education Research, 1 (1), 230-240.

-Enflasyon oranını, en düşük enflasyona sahip üç üye ülkenin yıllık enflasyon oranları ortalamasının 1.5 puandan fazla olmamalıdır,

-12 aylık dönem itibarıyla, uzun vadeli faiz oranları, fiyat istikrarı bakımından en iyi performans gösteren 3 üye ülkenin faiz oranından 2 puan fazla olmamalıdır,

-Parasının, son 2 yılda diğer üye ülke parası karşısında devalüe edilmemiş olmalıdır.

İlk iki kriter aşırı bütçe açıklarına bağlı mali istikrarı, son üç kriter parasal istikrarı sağlamak için uygulanmasına karar verilmiştir (Paleta, 2012,s.93).

Çok uluslu entegrasyonlarda üye devletlerin ortak bir para politikası ve ekonomi politikaları uygulaması Ekonomik ve Parasal Birlik (EPB) olarak ifade edilmektedir. Çok uluslu bütünleşme sürecinde, üye devletlerarasında gönüllü ortak kurumlar oluşturulur ve bu kurumlar; ortak hedefleri gözeten ve ortakçı karlara hizmet eden müşterek politikalar oluşturur. İleri düzeyde ekonomik bütünleşme sürecinde çok sayıda ülke yer aldığından, aralarındaki bağların kademeli olarak yar oluşturulması gerekir. 'EPB'de, üye ülkelerde ekonomik liberalizasyonun gerçekleşmesi ve güçlü para düşüncesinin yerleştirilmesi açısından ilişkiler çeşitlilik göstermektedir. Sonuçta, hazırlanan ve uygulanan ortak yasa ve politikalarla, üye devletlerin ekonomik faaliyetleri, kurumsal yapısı ve ülke vatandaşlarının günlük yaşamaları etkilenecektir. Para politikası, maliye politikası ve döviz kuru politikası bir ekonominin yönetiminde kullanılan başlıca politikalardır. EPB bölgesi olan Euro alanın oluşturulması ile bu ekonomi politikaların bazılarının ulusal düzeyde kullanımı sona ermiş̧tir. Bu bağlamda, Euro alana dâhil olan ülkelerde en önemli değişim;

1. Ortak para olarak Euro kabul edilmiş

2. Para politikası kullanım yetkisi Avrupa Merkez Bankası'na devredilmiştir (Akçay, 2006,s.17).

Maastricht Antlaşması ile para politikasında merkezileşme benimsenirken, maliye politikalarının üye ülkelerin yetkileri dahilinde yürütülmesine karar verilmiştir. Bu antlaşma ile, "Subsidiarity ilkesi" (yetki ikamesi ilkesi) yürürlüğe girerek ulusal maliye politikalarına büyük ölçüde özerklik tanınmıştır. Avrupa Birliği üye ülkelerine maliye politikası alanında tanınan bu özerkliğin en belirgin avantajı, para politikası uygulamasında kaybedilen yetkilerin ekonomik anlamda ortaya çıkabilecek asimetrik şokları bertaraf edecek önlemleri dinamik bir şekilde alabilecek maliye politikaları üretebilmeleri olmuştur. Ancak özerk maliye politikası ve yetki ikamesi ilkesinin sıkı bir şekilde uygulanmasının, bütünleşmenin ve ortak iktisat politikalarının geleceğini tehlikeye sokacak olumsuz sonuçlara yol açabilmektedir (Yıldız, 2011, s.115-116). Bunun en bariz göstergesi Yunanistan krizidir. Avrupa Birliği'nde 2002 Yılından bu yana ortak para (Euro) ve para politikasını yürütecek tek merkez bankası uygulaması başarılı bir şekilde hayata geçmiştir. Ancak aynı başarıyı maliye politikalarında görmek mümkün olmamıştır. Avrupa Birliği gerek vergi politikalarında gerek kamu harcamaları ve borçlanma politikalarında kâğıt üzerinde gösterdiği hassasiyeti uygulamada gösterememiş bu yüzden Yunanistan ağır borç yükü altında ekonomik krize girmiştir.

\section{Yunanistan ekonomisi neden bu duruma geldi?}

Yunanistan AB ile ilişkisini 1974'te, Albaylar cuntası'nın başarısız Kıbrıs çıkışı sonucunda düşmesiyle, yeniden kurdu. Ada'da darbeci Nikos Samson'a verdiği açık destek Cunta'nın sonu 
Karacan, R., Uğurkan, E. (2015). Avrupa Birliği ekonomik entegrasyon sürecinde ortaya çıkan problemlerin Yunanistan örneği bağlamında değerlendirilmesi. International Journal of Social Sciences and Education Research, 1 (1), 230-240.

ve Yunanistan için de yeni bir başlangıç oldu. Konstantin Karamanlis'in önderliğinde AB üyeliğini hızlandırdı. 1 Ocak 1981'de üye oldu. Üyelik öncesi ve sonrasında ülkenin Osmanlı'dan miras kalan kemikleşmiş sorunlarının, hiçbirinin üzerine gidilmediği gibi, kontrolsüz akan mali kaynaklar, var olan siyasi, iktisadi ve içtimai yapıları pekiştirdi. Euro Bölgesine dahil olma; 1981'de hemen hemen hiç reform yapmayan ve ekonomik verilerle oynayarak AB'yi yanıltan Yunanistan için, tam bir "ölümcül tuzak" oluşturdu. Bugün Syriza hükümetine dolayısıyla Yunanistan'a acı reçete uygulatan AB, 1981'den bu yana Yunanistan'da iktidar olanların uygulamalarını hiç denetlememiştir (Aktar, 2015).

Böylece bu gidişat bir noktada tıkanmış, Yunanistan ekonomisi 2008 yılında resesyona girmiştir. Bu süreçte Yunan ekonomisi \%25 küçülmüştür. Bu durum 1929 Büyük Buhrana yakın bir küçülmedir. Zira 1929 ABD ekonomisi benzer bir şekilde \%26 küçülmüştü. İşsizlik oranı \%28, genç işsizlerin oranı ise \%60'ı bulmuştur. İşsizliğin artmasıyla birlikte ücretler düşerken yoksul sayısı da artmıştır (Harari, 2015,s.6-7). Yunanistan diğer ülkelerle kıyaslandığında farklı bir yapıya sahip olduğu hemen göze çarpmaktadır. Zira Yunanistan 1981'yılından bu yana Avrupa Birliği ülkesidir. 2002 yılı itibari ile kendi ulusal parası Drahmiden vazgeçip Avrupa Birliği ortak parası olan Euro'yu kabul etmiştir. Dolayısıyla bir manada bağımsız para politikası uygulamasından vazgeçmiş para politikası ile ilgili uygulamalarını bir üst kuruluşa; Avrupa Birliği Merkez Bankası'na devretmiştir. Aslında bu uygulamanın hem olumlu hem de olumsuz tarafları mevcuttur. Olumlu tarafı siyasi otoritenin gelişigüzel parasal genişlemeye gidememesi, olumsuz tarafı bağımsız para politikası uygulamalarından yoksun kalınmasıdır. Son ekonomik krizle birlikte Yunanistan hükümeti gerek memurlarının gerekse emeklilerinin maaşlarını kısmen de olsa ödeyememiştir. Zira bu durum bağımsız merkez bankası olan bir ülkede olsaydı, sonuçları olumsuz da olsa para basmak suretiyle çalışanların ve emeklilerin maaşları ödenirdi. Aslında bu durum Avrupa Birliği’nin uygulamış olduğu para politikasının ciddi bir göstergesidir.

Yunanistan'ın bu duruma gelmesinde asıl belirleyici olan yüksek boyutlara ulaşan borç yükü ve bütçenin açığıdır. Zira Avrupa Birliği Maastricht Kriterlerine göre borcun GSMH'a oranında üst sınırın \%60 olmadır. Bu durum Yunanistan'da \% 170'lere ulaşmıştır. Yunanistan ekonomisinde yüksek kamu borcu ile bütçe açığı birbirini destekler hale gelmiş ve yunan ekonomisi "yüksek bütçe açığı-yüksek kamu borcu-artan faiz ödemeleri-yüksek bütçe açı̆̆ı-yüksek kamu borcu" şeklinde kısır birdöngüye girmiştir (Tablo 1). Bu kısır döngü, ekonomi yönetiminin izlediği politikalarla daha da karmaşık bir hal almıştır. Yunanistan'da birbirini takip eden hükümetler tarafından izlenen popülist politikalar sonucunda, gereksiz kamu tüketimi artmış; bütçe gelirlerinin üzerinde harcamalar yapılmış; vergi gelirleri de istenilen düzeyde toplanamamıştır. Nitekim 2006 yılında, Avrupa Komisyonu Yunanistan'da toplanmayan vergi gelirinin GSYİH'nin \%3,4'ü olduğunu belirtmiştir. Yunanistan'da diğer AB ülkelerine benzer vergi oranlarının uygulanmasına rağmen yeterli vergi geliri elde edilememesinin sebepleri arasında, ülkede kamu bütçesinin yönetiminde etkin olmayan denetim yapısı ve buna bağlı vergi kaçakçılığı yer almaktadır. Başa geçen hükümetler vergi kaçağını azaltabilecek önlemler yerine vergi oranlarını yükselterek vergi gelirlerini artırmayı hedeflemiştir (Akçay, 2012,s. 28). 
Karacan, R., Uğurkan, E. (2015). European economic integration process problems arising in the context of Greece case evaluation. International Journal of Social Sciences and Education Research, 1 (1), 230-240.

Tablo 1. Yunanistan bütçe dengesi, GSYİH büyüme ve borç-GSYİH oranı (2001-2014)

\begin{tabular}{|l|c|c|c|c|c|c|c|c|c|c|c|c|c|c|}
\hline Yunan ulusal hesap & $\mathbf{2 0 0 1}$ & $\mathbf{2 0 0 2}$ & $\mathbf{2 0 0 3}$ & $\mathbf{2 0 0 4}$ & $\mathbf{2 0 0 5}$ & $\mathbf{2 0 0 6}$ & $\mathbf{2 0 0 7}$ & $\mathbf{2 0 0 8}$ & $\mathbf{2 0 0 9}$ & $\mathbf{2 0 1 0}$ & $\mathbf{2 0 1 1}$ & $\mathbf{2 0 1 2}$ & $\mathbf{2 0 1 3}$ & $\mathbf{2 0 1 4}$ \\
\hline Kamu gelir (GSYiH'nin \%) & 41.3 & 40.6 & 39.4 & 38.4 & 39.0 & 38.7 & 40.2 & 40.6 & 38.7 & 41.1 & 43.8 & 45.7 & 47.8 & 45.8 \\
\hline $\begin{array}{l}\text { Kamu harcamaları } \\
\text { GSYIH'nin \%) }\end{array}$ & 45.8 & 45.5 & 45.1 & 46.0 & 44.4 & 44.9 & 46.9 & 50.6 & 54.0 & 52.2 & 54.0 & 54.4 & 60.1 & 49.3 \\
\hline Bütçe dengesi (GSYIH'nin \%) & -4.5 & -4.9 & $-5,7$ & $-7,6$ & -5.5 & -6.1 & $-6,7$ & $-9,9$ & $-15,3$ & $-11,1$ & $-10,2$ & $-8,7$ & $-12,3$ & -3.5 \\
\hline Yapısal denge (GSYIH'nin \%) & -4.9 & -4.5 & $-5,7$ & $-7,7$ & -5.2 & -7.4 & $-7,8$ & $-9,7$ & $-14,7$ & -9.8 & $-6,3$ & -0.6 & 2.2 & 0,4 \\
\hline $\begin{array}{l}\text { Nominal GSYiHbüyümesi } \\
\text { (\%) }\end{array}$ & 7.2 & 6.8 & 10.0 & 8.1 & 3.2 & 9.4 & 6.9 & 4,0 & -1.9 & -4.7 & $-8,2$ & -6.5 & -6.1 & -1.8 \\
\hline GSYH fiyat deflatörü (\%) & 3.4 & 3,5 & 3.2 & 3,0 & 2.3 & 3.4 & 3.2 & 4.4 & 2.6 & 0,8 & 0,8 & 0.1 & -2.3 & -2.6 \\
\hline Reel GSYï büyüme (\%) & 3.7 & 3.2 & 6.6 & 5.0 & 0.9 & 5.8 & 3,5 & -0.4 & -4.4 & -5.4 & $-8,9$ & -6.6 & -3.9 & 0,8 \\
\hline Kamu borcu (milyar €) & 152.1 & 159.5 & 168.3 & 183,5 & 212,8 & 225,3 & 240.0 & 264,6 & 301,0 & 330,3 & 356,0 & 304,7 & 319,2 & 317.1 \\
\hline Nominal GSYH (milyar €) & 152.0 & 162.3 & 178.6 & 193.0 & 199.2 & 217,8 & 232,8 & 242,1 & 237,4 & 226,2 & 207,8 & 194.2 & 182,4 & 179.1 \\
\hline Borç-GSYiH oranı (\%) & 100.1 & 98.3 & 94.2 & 95.1 & 106.9 & 103.4 & 103.1 & 109.3 & 126.8 & 146.0 & 171.4 & 156.9 & 175.0 & 177.1 \\
\hline $\begin{array}{l}\text { - Nominal GSYiH büyümesin- } \\
\text { in (\%) etkisi }\end{array}$ & $-6,7$ & $-6,3$ & -9.0 & -7.1 & -2.9 & $-9,2$ & $-6,7$ & -3.9 & 2.1 & 6.3 & 13.0 & 12.0 & 10.1 & 3.3 \\
\hline - Hisse Senedi akış ayarı (\%) & 2.7 & -0.3 & -0.8 & 0.3 & 9.2 & -0.4 & -0.4 & 0.3 & 0.0 & 1.9 & 2.1 & $-35,1$ & -4.4 & -4.7 \\
\hline - Bütçe dengesi (\%) etkisi & 4,5 & 4.9 & 5.7 & 7.6 & 5.5 & 6.1 & 6.7 & 9.9 & 15.3 & 11.1 & 10.2 & 8.7 & 12.3 & 3,5 \\
\hline $\begin{array}{l}\text { - Genel olarak yllık oran } \\
\text { değişikliği (\%) }\end{array}$ & 0,4 & -1.8 & -4.0 & 0,8 & 11.8 & -3.4 & -0.4 & 6.2 & 17.5 & 19.2 & 25.3 & $-14,5$ & 18.1 & 2.1 \\
\hline
\end{tabular}

Kaynak: Eurostat and European Commission

Bütünleşmenin bugünkü durumu ile Avrupa Birliğinin krize karşı yaklaşımı ve çözüm arayışı arasında, yakın ilişki vardır. Bilindiği üzere, Maastricht Antlaşması ile üye ülkelerin maliye politikalarının yürütülmesi konusunda özerklikleri korunmuş; maliye politikaları ile ilgili (bütçe açığı/GSYH ve kamu borcu/GSYH) bir takım sınırlamalar getirilmiştir. Ancak küresel finans krizinde bu sınırlamalara pek uyulmamıştır. Bütün üye ülkelerin farklı maliye politikaları izlemeleri, Birlik genelinde krize karşı alınacak önlemlerde ortak çözüm üretilmesini güçleştirmekte ve bu durum maliye politikası alanında daha güçlü bir koordinasyonun gerekliliğini ortaya çıkarmaktadır (Bakar ve Tokatlığlu; 2012, s.484-485).

Yunan halkı sosyolojik açıdan değerlendirildiğinde Akdeniz insanının tüm özelliklerini taşımaktadır. 1. Siesta kültürü 2. Sabahlara kadar sirtaki-uzo eşliğinde eğlenme. Yani iktisat sosyoloji çerçevesinde değerlendirdiğimizde kazandıklarını fazla harcayan bir halk mevcut (Paçal, 2015).

Troyka denilen, IMF, Avrupa Merkez Bankası ve Avrupa Birliği üçlüsü ile yapılan kurtarma anlaşması; kamu harcamalarının kısılması, asgari ücretin indirilmesi, kamu varlıklarının özelleştirilmesi, işgücü piyasasında toplu pazarlığa son verilmesi, emekli maaşlarının azaltılması koşullarına bağlanmıştı. Fakat uygulanan bu koşullar ekonomide küçülmeye neden oldu. 2010'dan günümüze yani 2015'e kadar Yunanistan ekonomisi reel olarak yüzde 25 küçüldü. Bu nedenle de ekonomi bir türlü rayına oturtulamadı. Kısaca IMF tahminleri tutmadı (Yaşar, 2015). 15 Temmuz 2015 parlamentodan Sriyza'nın iç muhalefetine Fakat diğer partilerinin desteği ile 300 sandalyeli parlamentoda 297 milletvekili oylamaya katılmıştır. Oylamada 222 milletvekilinin "evet" oyu ile kabul edildi. Fakat parti içi muhalefet nedeniyle 20 Eylül 2015 için erken seçim kararı aldı.

Eurogrup'ta varılan anlaşma dahilinde Yunanistan varlıklarının değerlendirilmesi, satılması ve özelleştirmesinde ile 50 milyar avroluk bir "Teminat Fonu” oluşturulmasına; Yunan yetkili ve kreditörlerden oluşacak fonun idare merkezi Atina'da olmasına ve ülkenin ekonomik anlamda istikrara ulaşması ve kreditörlerin paralarını geri alacaklarını garantilemeleri anlamına gelen "Teminat Fonu'nun" merkezinin Brüksel'de olmasına ilişkin talepler Cipras tarafindan kabul edilmemiştir. Yunan Başbakan "Egemenlik haklarımızdan vazgeçmeyeceklerini ifade etmiştir. Kamu 
Karacan, R., Uğurkan, E. (2015). Avrupa Birliği ekonomik entegrasyon sürecinde ortaya çıkan problemlerin Yunanistan örneği bağlamında değerlendirilmesi. International Journal of Social Sciences and Education Research, 1 (1), 230-240.

varlıklarının değerlendirilmesini hedefleyen fon, Atina'dan yönetilecek ancak idaresinde Yunanlar ve kreditörler birlikte çalıştırılmasına; buradan sağlanacak 25 milyar Euro bankaların sermaye artıımında, 12,5 milyar Euro'nun ise ekonominin kalkınmasında kullanılmasına karar verilmiştir (Sancak, 2015).

Fakat bazı iktisatçılar, ülkenin bir daha büyüme göremeyeceği halkın daha da fakirleşeceğini ve hatta Yunanistan'ın daha da radikalleşebileceğini iddia etti. Bütün bunlar Yunanistan'ın Avro Bölgesinde kalabilmek için ödeyeceği bedel olduğu belirtildi Yunanistan'ın 50 milyar avroluk özelleştirme yapamayacağını ve AB ile Yunanistan arasındaki kredi anlaşmasının ya da söz konusu kurtarma paketinin öncekilerden daha yumuşak olmadığını. 50 milyar avroluk özeleştirmenin Yunan gayr-i milli hâsılasının neredeyse üçte birine denk geldiği. Dahası ultra sol olarak bilinen hükümetin bu özelleştirme paketinde ne kadar samimi olacağıdır. Eğer yeterli kontrol sağlanamazsa da bankalar iflas edebilir. Yeni paket sermaye kontrollerini öngörüyor, Yani Yunanistan'da halkın bankalardan para çekişi bir süre daha kontrolle sağlanacak. Yunanistan gibi nakit üzerinde dönen ülke için bu, durgunluk ve ekonomik küçülme anlamına geliyor. Öte yandan diğer önemli nokta, Yunan bankalarının tekrar sermayelerinin güçlendirilmesidir. Kredibilitelerinin yanı sıra sermayelerinin de birçok kısmı erimiş olan Yunan bankalarının en kısa zamanda fonlaşması gerekir. Aslında AB'nin Yunanistan'ın kurtarma paketinde koyduğu sermaye kontrollerinin amacı da halkın bankalardan tüm mevduatlarını çekme riskini azaltmaktır. Çünkü böyle bir durumda Yunan bankalarının iflas etmesi kaçınılmazdır. Ekonomide 'run on bank' olarak anlatılan bu durum, Yunanistan'da gerçekleşmeye çok yaklaşmıştır”' (Özsöz, 2015).

\section{5. Çözüm önerileri, olasılıklar ve sonuç}

Avrupa Birliği son Yunanistan krizi ile ekonomik bütünleşmeyi tam olarak sağlayamadığı gerçeği ortaya çıkmıştır. Parasal birlik olma yolunda ciddi adımlar atılsa da mali anlamda ve siyasi alanda aynı başarı gösterilememiştir. Birliğe giriş ilkesi olarak şart koşulan üst sınırı \% 60 ' lık borç yükü ve \% 3'lük bütçe açığı GSYİH oranı gibi mali kriterlerinin sadece giriş koşulları olduğu; üyelik sürecinde bu koşullara uyulmadığı; dolayısıyla uygulamaların kâğıt üzerinde kaldığı görülmüş̧ür. Bu bağlamda öncesinde alınmayan önlemlerin kriz sonrası tabiri caiz ise faturası ağır olmuştur. Avrupa Birliği bu olaydan ders çıkartarak para politikalarında gösterdiği hassasiyeti maliye politikalarında göstermelidir. Tüm üye ülkelerin vergileme, kamu harcamaları ve kamu borçlanma politikalarının tek elden yürütüleceği Avrupa Merkez Bankası ayarında maliye bakanlığı niteliğinde bir mali kurum oluşturulmalı bu yolla üyelerin maliye politikaları denetim altına alınmalıdır. Gerçi AB'nin tarihsel süreci temel alındığında, her kriz sonrası kendini yenileyerek daha da güçlenerek yeni atılımlar ve kararlar alınması firsatı sunmuştur. Hatta Yeni kurumlar ortaya çıkmıştır. Bu nedenle de, AB açısından daha esnek politikalardan ziyade daha katı ve kontrol mekanizmasını işleten buna uymayan ülkeleri yaptırıma tabi tutan bir tavır söz konusudur. Bunu da kurumsallaştırmış ve krizle birlikte daha işler hale getirmiştir. Zira 13 Temmuz 2015'te Yunanistan ile AB'nin imzaladığı Üçüncü mali pakette bu denetim ve kontrole sıkça vurgu yapilmaktadır.

Yunanistan, eğer Almanya'nın isteği doğrultusunda Yunanistan avro Bölgesi'nden beş yıl süreyle geçici olarak çıkarılsaydı.

1. Yunanistan Rusya'ya yakınlaşabilirdi. Zira kriz sürecinde Yunanistan bu kartını oynayabileceği sinyallerini vermiştir. Bu nedenle Yunanistan krizinin görünen ekonomik etkilerin yanında 
Karacan, R., Uğurkan, E. (2015). European economic integration process problems arising in the context of Greece case evaluation. International Journal of Social Sciences and Education Research, 1 (1), 230-240.

en az ekonomik etkiler kadar etkili siyasi etkileri de olabilirdi. Bu da entegrasyon sürecinde olan AB'için geri adım olacaktı. AB'nin bu süreçteki enerjisi önemli ölçüde kırılmış olacaktı.

2. Yunanistan Avro Bölgesi’nden çıkmış olsaydı. Avro'ya güven azalırdı. Çünkü Avro Bölgesinin zayıf ülkeleri İspanya, Portekiz, İtalya, İrlanda, Slovenya, Slovakya, Letonya, Litvanya, Malta ve Kıbrıs'a piyasa baskısı artacaktı. Borçlanmalarını bu ülkeler ancak yüksek faizlerle yapabilecekti. Tabii bu arada bankalar ve alacaklılar için yeni endişeler ortaya çıkacaktı (Yaşar, 2015). Avrupa ekonomisinin bu süreçte iyileşmesi daha güç olacaktı. Zaten Avrupa'nın doğusunda Rusya'ya uygulanan ambargo nedeniyle ekonomide ortaya çıan yeni sorunlar bu defa kendi içersinde yeni bir krize dönüşecekti.

3. Üçüncü kurtarma paketinde varılan uzlaşmaya göre, Yunan tarafının sadece iki talebi kabul edildi. "Troyko" yerine kullanılan terim "Kurumlar", diğeri ise Yunan hükümetinin vaat ettiği cari fazlası 3,5 'tan yüzde 1,5'e indi. Bunların dışında bütün eski şartlar geçerliliğini korudu. Yunanistan, bankalar ve borsa rahatlarken AB'de siyasi açıdan bir krizi atlatmış oldu. Eurogroup ile mutabakat sağlanınca Syriza Partisi içinde yeni bir muhalefet ortaya çıktı. Bu olasılığa hazır olan 'troyko' ya da üçüncü paketten sonra resmi adıyla anılan kurumlar, para yardımını reformların uygulanmasına bağladı. Vaat edilen 7,2 milyar avronun hemen değil, bütün reform tedbirleri uygulandıktan sonra verileceği anlaşıldı. Çetin bir müzakere sürecinden sonra da olsa yine AB'nin dediği oldu. Fakat uzun vadede ise, Yunan ekonomisini de derinden etkileyeceği kadar Yunan iç siyasetini de doğrudan etkileyecek pakettir. 2015 Eylülünde tekrar Seçimler yapılması en iyi örnektir. Bu karar Syriza'nın hem iç muhalefete yönelik hem de halkın, reform uygulamalarına izin verip vermemesi ile ilgilidir. Çünkü Syriza söylemlerinden çok farklı bir anlaşmaya imza atmıştır (Grigoriadis, 2015).

\section{Kaynakça}

Akçay, B. (2006). Euro Alanın Ekonomisine İlişkin Bir Değerlendirme, Ankara Avrupa Çalışmaları Dergisi Cilt: 5, No:2, 1-27.

-, (2012). Yunanistan Ekonomisinde Devlet Borç Krizi-Cari Açık İlişkisi, Maliye Dergisi, Sayl:163, 1535 .

Aktar, C. (7 Temmuz 2015).Yunanistan Şimdi Avrupalaşacak, Taraf Gazetesi.

-, (14 Temmuz 2015). Alman AB, Taraf Gazetesi.

Arısan, E. N.(2010). Avrupa Birliğinde Neler Oluyor, TEPAV Değerlendirme Notları.

Bakar, F., \& Tokatlığlu, Y. M. (2012). Küresel Finansal Kriz Sürecinde Avrupa Birliği Vergi Politikaları, Maliye Dergisi, Sayl:163, 481-504.

Brou, D., \& Michele, R. (2007). Economic Integration, Political Integration Orboth? Journal of the European Economic Association, Vol. 9(6), 1143-1167.

Cornia, G. A. (2011). Economic Integration, Inequality and Growth: Latin America vs. the European Economies in Transition, DESA Working Paper No. 101.

Daniel, H. (2015). Greek Debtcrisis: Background and Developments in Briefing Paper, Number:7114.

Ernst, B. H. (1958). The Uniting of Europe, Political, Socialand Economic Forces 1950-1957, University of Notre Dame Press Notre Dame, Indiana.

Ionnis, N. G. Erken Seçim Yeniden, www.batitrakya.org. Erişim Tarihi:17.09.2015.

-, Yunanistan Krizinin Yapısal Nedenleri, www.batitrakya.org. Erişim Tarihi: 19.09.2015. 
Karacan, R., Uğurkan, E. (2015). Avrupa Birliği ekonomik entegrasyon sürecinde ortaya çıkan problemlerin Yunanistan örneği bağlamında değerlendirilmesi. International Journal of Social Sciences and Education Research, 1 (1), 230-240.

-, (2 Mart 2015). SYRİZA’nın Gerçekle İmtihanı, Taraf Gazetesi.

Miroslav, N. J. (2004). Economic integration and spatial location of production, University of Genoa, Department of Economics and Finance Working Paper No. 12.

-, (2005). Turkey in the European Union: Euthanasiaor the Rejuvenation of Europe? Associazione Universitariadi Studi Europei (AUSE), Scuola Estivadi Venezia.

Öniş, Z., \& Kutlay, M. (2012). Ekonomik Bütünleşme/Siyasal Parçalanmışlık Paradoksu: Avro Krizi ve Avrupa Birliği'nin Geleceği, Uluslararası ilişkiler, Cilt 9, Sayı 33, 3-22.

Özdemir, H. (2002). Avrupa Mantığ1; Avrupa Bütünleşmesinin Teori ve Dinamikleri, Boğaziçi Üniversitesi Yayınevi, Birinci basım, İstanbul.

Özsöz, E. (17 Temmuz 2015). Yunanistan'da Halk Daha da Fakirleşecek, Taraf Gazetesi.

Paçal, M. (2015). “Taverna Ekonomisi ve Syriza”, Taraf Gazetesi.

Paleta,T.(2012). Maastricht Criteria of Divergence? Review of Economic Perspectives, Vol. 12, Issue 2, 92 119.

Prammer, D.(2009). Öffentliche Ausgliederungen: Bilanz kosmetik oder nachhaltige Verbesserung? : Fall studie für Österreich, Geldpolitik \& Wirtschaft : Quartal sheftzur Geld und Wirtschaftspolitik, 125-143.

Sancak, M. (14 Temmuz 2015). Pek Çok Euro Bölgesi Yunanistan'ı İzlemeye Hazır, Habertürk Gazetesi.

Yaşar, S. (19 haziran 2015). Sağcılar Yunanistan21n İflasını İstiyor, Taraf Gazetesi.

Yıldız, H.(2011). Avrupa Birliği’nde Maliye Politikalarının Uyumlaştıılması, Ç.Ü. Sosyal Bilimler Enstitüsü Dergisi, Cilt.20, Sayı.2, 111-134. 
Karacan, R., Uğurkan, E. (2015). European economic integration process problems arising in the context of Greece case evaluation. International Journal of Social Sciences and Education Research, 1 (1), 230-240.

\section{Extended abstract in English}

In the common characteristic structure of economic and political formations, it is possible to see geographic proximity, common history, common culture, language and religious elements together. Communities that are formed, in this way, by a combination of more than one country aim to ensure economic, political and military superiority over other countries that do not involve in or over the big countries that they cannot fight alone.

In order to prevent possible problems and help coal and steel to be distributed by one entity, which were the most important industrial raw materials after the second world war period, the European Coal and Steel Community was established among Germany, France, Italy, the Netherlands, Belgium and Luxembourg. Thus, it was the first step to the European Union. In the later period, with the aim of creating economic unity in other sectors as well as in coal and steel, the Treaty of Rome was signed, which led to the creation of the European Economic Community (EEC) in 1957. In 1958, the Atomic Energy Community was founded. In the course of time, these three foundations were combined together under the name of the European Community and continued their activities. Meanwhile, the Community enlarged to include various countries. In 1981, Greece became the member of the European Community. The European Community, which was named as the "European Union" in 1995, first aimed at monetary and economic integration, then politiacal unity.

While ratifying process of the Treaty of Lisbon was continuing, a financial crisis hit the EU countries' economy. In the beginning, it was considered as "Anglo-Saxon Capitalism as it would not affect Continental Europe but through time it dramatically increased the EU issues. Especially the issues due to the crisis occuring in Southern European Countries - members of the Unionnegatively affected the economic integration process. (Arisan, 2010, p.2). Particularly Greece and the European Union in the leadership of Germany, enforced strict austerity policy or austerity measures against these countries. Countries such as Spain and Portugal entered the recovery process by these measures in spite of the bitter political costs. For Greece, this process developed differently. Greece applied the strict measures of the Union. Greek Government under the leadership of New Democracy Party paid a heavy price for it at the last election ending in defeat. Syriza under the leadership of Tsipras, which developed a discourse against the economic measures suggested by the European Union, won the election. After this process, developments such as Greece resisting the measures but failing to get rid of the crisis and holding a referendum in order to quit monetary union brought the economic integration to standstill while aiming at political unity. In this study, for this purpose, it will be explained with examples that the European Union has not grown to neither economic nor political maturity, based on Greek example.

It has come in sight that the European Union has not entirely realized economic integration with the last Greek crisis. Even though there are important steps taken towards monetary union, the same success could not be displayed in neither economic nor political field. It is clearly seen that financial admission criteria such as the upper limit of $60 \%$ debt, $3 \%$ of fiscal deficit and GDP rate just remained as admission conditions and these conditions were not complied with during the membership. Thus, it can be said that these applications were just on paper. In this context, cautions that had not been taken beforehand affected the states negatively after the crisis. The European Union need to take a lesson from this event and should show the same sensitivity in fiscal policy as in monetary policy. A financial institution which is in the form of European Central Bank and in the status of Ministry of Finance should be established in order to carry taxation, 
Karacan, R., Uğurkan, E. (2015). Avrupa Birliği ekonomik entegrasyon sürecinde ortaya çıkan problemlerin Yunanistan örneği bağlamında değerlendirilmesi. International Journal of Social Sciences and Education Research, 1 (1), 230-240.

public expenditures and public debt policies of all the member states in one hand. Also the fiscal policies of all the member states should be regulated by this way. However, when we consider the EU's historical process, we can see that the European Union has offered many opportunities to take new steps and make new decisions by renewing itself and growing stronger after each crisis. Even new institutions were established. Therefore, we can suggest that the Union is in favour of rigid policies and control mechanism rather than flexible policies against the states that do not apply the sanctions. The Union also institutionalized this and made it more functional after the crisis. It is clearly seen that these regulations and control mechanism were so often emphasized on the third financial package signed by Greece and the EU on 13th July 2015. 